\title{
Intelligent Multimodel Simulation in Decomposed Systems
}

\author{
Esko K. Juuso \\ Control Engineering, Faculty of Technology, University of Oulu, Finland, esko. juuso@oulu.fi
}

\begin{abstract}
Intelligent methodologies provide a good basis for multimodel simulation. Small, specialised systems have a large number of feasible solutions, but developing truly adaptive, and still understandable, systems for highly complex systems require domain expertise and more compact approaches at the basic level. The nonlinear scaling approach extends the application areas of linear methodologies to nonlinear modelling and reduces the need for decomposition with local models. Fuzzy set systems provide a good basis for understandable models for decomposed systems. Data-based methodologies are suitable for developing these adaptive applications via the following steps: variable analysis, linear models and intelligent extensions. Complex problems are solved level by level to keep the domain expertise as an essential part of the solution.
\end{abstract}

Keywords: nonlinear systems, intelligent methods, composite local modelling, linguistic equations, fuzzy logic

\section{Introduction}

Models are understood as relationships between variables and used to predict properties or behaviour of the system. Variable interactions and nonlinearities are important in extending the operation areas (Juuso, 2004a). Phenomenological models based on physics, chemistry and mathematics require domain expertise (Figure 1). Linear methodologies extended with principal components (Jolliffe, 2002; Gerlach et al., 1979) and semi-physical models (Ljung, 1999) provide a feasible solution for many applications. Nonlinearities have been handled commonly with interaction and quadratic terms (Box and Wilson, 1951). Linear parameter varying (LPV) extend these solutions to decomposed systems (Hjartarson et al., 2015; Theis et al., 2018).

Artificial neural networks (ANNs) starting from (Rummelhart et al., 1986) continue this by using more complex architectures with deep learning for complicated interactions within different sources of varying data (Schmidhuber, 2015). Big data analytics and deep learning are in high focus in data science (Najafabadi et al., 2015).

Knowledge-based information can be handled with fuzzy set systems introduced by Zadeh (1965): numerous methodologies have been developed, see (Takagi and Sugeno, 1985; Driankov et al., 1993; Dubois et al., 1999), and combined with neural networks (Fullér, 2000). Different fuzzy approaches can be efficiently combined (Juuso, 2014).
First order ordinary differential equations are solved by numerical integration and special solutions have been developed for identification (Ljung, 1999). These approaches, which are also used in fuzzy set systems (Babuška and Verbruggen, 2003) and low complexity neural networks (Sahoo et al., 2013), define structures for hybrid dynamic models (Figure 1). Local models need to be combined in complex systems (Sontag, 1981; Ljung, 2008; Jardine et al., 2006).

The linguistic equation (LE) approach originates from fuzzy set systems (Juuso and Leiviskä, 1992): rule sets are replaced with equations, and meanings of the variables are handled with scaling functions which have close connections to membership functions (Juuso, 1999a). The nonlinear scaling technique is needed in constructing nonlinear models with linear equations (Juuso, 2004a). Constraints handling (Juuso, 2009a) and data-based analysis (Juuso and Lahdelma, 2010), improve possibilities to update the scaling functions recursively (Juuso, 2011). The LE approach together with knowledge-based systems, neural networks and evolutionary computation form the computational intelligence part (Figure 1).

Three levels of smart adaptive systems (SAS) are identified in (Anguita, 2001): (1) adaptation to a changing environment, (2) adaptation to a similar setting without explicitly being ported to it, and (3) adaptation to a new or unknown application. The smart use of intelligence by integrating specific intelligent systems is essential in the development of complex adaptive applications. Implementation of smart adaptive systems on silicon has been proposed to to adapt perceptual and cognitive tasks autonomously to the changing environment (Valle, 2004).

Technically, an automatic black box modelling could be possible in various big data problems by using combinations of these methodologies. The domain expertise is an essential part in integrated solutions to understand and assess the applicability. This paper classifies modelling methodologies and focuses on the nonlinear scaling and integrates the LE approach into the modelling applications for complex systems. Various applications are shortly discussed.

This paper focuses on the LE modelling approach enhanced with statistical and knowledge-based methodologies within decomposed systems (Section 2). Different methodologies are combined in the multimodel LE simulation (Section 3). Various applications summarised in Section 4 are discussed in Section 5. Conclusions and future research presented in Section 6. 


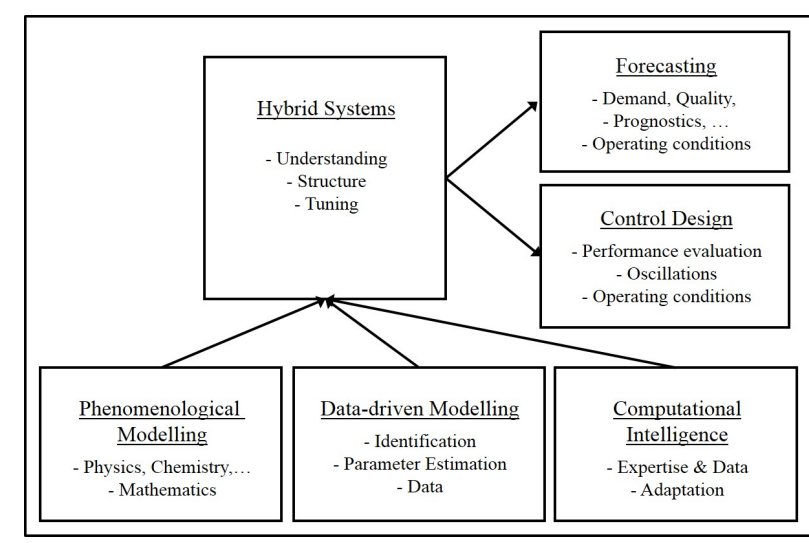

Figure 1. Methodologies and application types of modelling and simulation, modified from (Juuso, 2004b)

\section{Modelling methodologies}

The modelling methodologies include statistical analysis, knowledge-based methodologies and decomposition solutions.

\subsection{Statistical analysis}

Nonlinear scaling and steady-state statistical modelling with linear methodologies are the basis of the LE modelling. Dynamic modelling introduces additional model structures.

\subsubsection{Nonlinear scaling}

The nonlinearities of the process are handled by the nonlinear scaling of the variables. The scaling functions are monotonously increasing functions $x_{j}=f\left(X_{j}\right)$ where $x_{j}$ is the variable and $X_{j}$ the corresponding scaled variable. The function $f()$ consist of two second order polynomials, one for the negative values of $X_{j}$ and one for the positive values, respectively. The corresponding inverse functions $x_{j}=f^{-1}\left(X_{j}\right)$ based on square root functions are used for scaling to the range $[-2,2]$, denoted linguistification. In LE models, the results are scaled to the real values by using the function $f($ ). (Juuso, 2004a)

The support area is defined by the minimum and maximum values of the variable, i.e. the support area is $\left[\min \left(x_{j}\right), \max \left(x_{j}\right)\right]$ for each variable $j, j=1, \ldots, m$. The central tendency value, $c_{j}$, divides the support area into two parts, and the core area is defined by the central tendency values of the lower and the upper part, $\left(c_{l}\right)_{j}$ and $\left(c_{h}\right)_{j}$, correspondingly. This means that the core area of the variable $j$ defined by $\left[\left(c_{l}\right)_{j},\left(c_{h}\right)_{j}\right]$ is within the support area. The parameters of the functions are extracted from measurements by using generalised norms and moments (Juuso and Lahdelma, 2010).

\subsubsection{Steady-state modelling}

The steady-state simulation models are linear multiple input, multiple output (MIMO) models $\vec{y}=F(\vec{x})$, where the output vector $\vec{y}=\left(y_{1}, y_{2}, \ldots, y_{n}\right)$ is calculated by a lin- ear function $F$ from the input vector $\vec{x}=\left(x_{1}, x_{2}, \ldots, x_{m}\right)$. Statistical modelling in its basic form uses linear regression for solving coefficients for a linear function. Linear methodologies are suitable for large multivariable systems. Quadratic and interactive terms are not used here. Principal components compress the data by reducing the number of dimensions with a minor loss of information (Jolliffe, 2002). Partial least squares regression (PLS) is an extension of these ideas (Gerlach et al., 1979). Known semi-physical models of inputs are important in linear modelling, see (Ljung, 1999).

\subsubsection{Dynamic modelling}

Data-driven modelling with parametric models, also known as identification (Ljung, 1999), is the key methodology in the dynamic modelling (Figure 1). Nonlinear scaling reduces the number of input and output signals needed for the modelling of nonlinear systems. For the default LE model, all the degrees of the polynomials become very low:

$$
Y(t)+a_{1} Y(t-1)=b_{1} U\left(t-n_{k}\right)+e(t)
$$

for the scaled variables $Y$ and $U$. Phenomenological models can be integrated with these solutions.

\subsection{Knowledge-based methodologies}

Knowledge-based information can be introduced by fuzzy logic which emerged from approximate reasoning: the connection of fuzzy rule-based systems and artificial intelligence $(A I)$ is clear, e.g. the vocabulary of AI is kept in fuzzy logic (Dubois et al., 1999). Fuzzy set theory first presented by Zadeh (1965) form a conceptual framework for linguistically represented knowledge.

Domain expertise can be combined with statistical models with following fuzzy methodologies:

- Linguistic fuzzy models (Driankov et al., 1993), where both, the antecedent and consequent are fuzzy propositions, suit well for natural language, heuristics and common sense knowledge.

- Takagi-Sugeno (TS) fuzzy models (Takagi and Sugeno, 1985), where each consequent $y_{i}, i=$ $1, \ldots, n$, is a crisp function of the antecedent variables $\vec{x}$, can integrate local linear models. A smoothing technique is needed for drastically different local models (Babuška, 1998).

- Singleton models can be regarded as special cases of both the linguistic fuzzy models and the TS fuzzy models.

The extension principle is the basic generalisation of the arithmetic operations if the inductive mapping $F\left(x_{j}\right)$ is a monotonously increasing function of the input. The interval arithmetic presented by Moore (1966) is used together with the extension principle on several membership 
$\alpha$-cuts of the fuzzy number $x_{j}$ for evaluating fuzzy expressions (Buckley and Qu, 1990; Buckley and Hayashi, 1999; Buckley and Feuring, 2000). The fuzzy sets can be modified by intensifying or weakening modifiers (De Cock and Kerre, 2004; Le and Tran, 2018)

Type-2 fuzzy models introduced by Zadeh (1975) take into account uncertainty about the membership function (Mendel, 2007; Sadeghian et al., 2013).

Dynamic fuzzy models use the same parametric structures as the statistical models (Babuška and Verbruggen, 2003; Sahoo et al., 2013).

\subsection{Decomposition}

Decomposition is needed to extend the solutions to different subprocesses, process phases, phenomena and multiple operating conditions.

\subsubsection{Subsystems}

Modelling problems are divided into smaller parts for developing separate models for subprocesses or different stages in the process operation interconnected with process streams. In addition to spatial or logical blocks, the decomposed modelling can be based on different frequency ranges. Cluster analysis provides hundreds of algorithms for the data-driven analysis (Xu and Tian, 2015). The mixed systems may also include models based on the first principles. Clustering is used in the data analytics to find feasible areas for local models.

\subsubsection{Composite local models}

The composite local model approach constructs a global model from local models, which usually are linear approximations of the nonlinear system in different neighbourhoods. If the partitioning is based on a measured regime variable, the partitioning can be used in weighting the local models. In linear parameter varying (LPV) models, the matrices of the state-space models depend on an exogenous variable measured during the operation (Hjartarson et al., 2015; Theis et al., 2018). Piecewise affine (PWA) systems extend the local linear models to a polyhedral partition where the models can be state-space or parametric models (Christophersen, 2007). The model switches between different modes as the state variable varies over the partition. However, a high number of local models brings an overfitting risk.

\subsubsection{Intelligent systems}

Composite local models enhanced with fuzzy set systems form feasible solutions to handle partially overlapping models. Fuzzy models combine local modelling approaches and facilitate gradual changes. The smoothing problem around the submodel borders of Takagi-Sugeno (TS) fuzzy models needs special techniques, e.g. smoothing maximum, or by making the area overlap very strong. The ANFIS method (Jang, 1993) is widely used in the tuning of TS fuzzy systems, but it increases the overlap of clusters and destroys the meanings of the individual linear models, e.g. the role of some submodels may transform

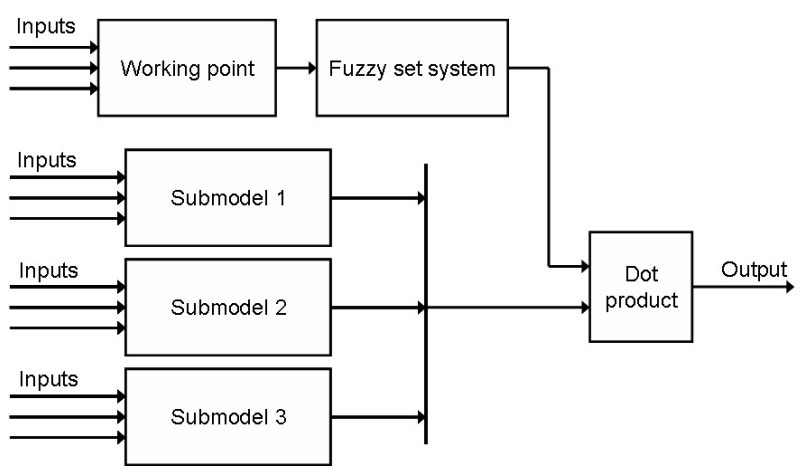

Figure 2. Multimodel LE system with a fuzzy decision module (Juuso, 2009b).

into a part of a smoothing algorithm. A Kalman-based learning algorithm has been proposed for online TS identification (Vafamand et al., 2018).

In multiple neural network systems, the task decomposition and an ensemble of redundant networks improve generalisation. Ensemble averaging is the process of creating multiple models and combining them to produce a desired output. Multimodel ensamble methods are important in deep neural networks (Xiao et al., 2018).

\section{Multimodel LE simulation}

A multimodel approach has been developed for combining specialised linguistic equation (LE) submodels where the nonlinear scaling need to be done by a set of functions due to very strong nonlinearities. Additional properties are achieved because equations and delays are allowed to vary between different submodels. In this multimodel approach, the working area is defined by a separate working point model. The submodels are developed using the casebased modelling approach.

\subsection{Fuzzy LE models}

The multimodel system contains several submodels and a fuzzy decision system for selecting and weighting suitable models for each situation using several working point variables. If several inputs are combined into a single working point index, the fuzzy set system is reduced to a fuzzification block.

Linguistic Takagi-Sugeno fuzzy models (LTS) belong to this class of models with one limitation: the fuzzy partition is defined with the same variables as the models. As LE models are nonlinear, the local models are also nonlinear. LTS models can be developed and tuned with the same methods as the normal TS models with one difference: the variable values are scaled with the nonlinear scaling functions. Correspondingly, the LTS models extend the normal LE model by handling the equation part with a fuzzy set system. (Juuso, 2009b) 
Table 1. Steady-state LE model applications.

\begin{tabular}{|c|c|c|}
\hline Case & Application area & Modelling \\
\hline Electric furnace & DSS for process design & $\begin{array}{l}\text { Nonlinear models transformed to LE models } \\
\text { Interactions }\end{array}$ \\
\hline Lime kiln & Feedforward control & Fuel feed in changing capacity conditions \\
\hline Solar collector field & Control adaptation & $\begin{array}{l}\text { Steady-state working point model: } \\
\text { Irradiation, temperature difference, } \\
\text { special cases with fuzzy set systems }\end{array}$ \\
\hline Continuous cooking & Quality control & Quality forecasting \\
\hline Fatigue & Stress contributions & $\begin{array}{l}\text { LE based stress-cycle curve } \\
\text { 2nd order and logarithmic scaling }\end{array}$ \\
\hline Water treatment & Feedforward control & $\begin{array}{l}\text { Turbidity for control } \\
\text { Forecasting residual aluminium }\end{array}$ \\
\hline Wastewater treatment & Diagnostics & Operating conditions \\
\hline
\end{tabular}

Table 2. Dynamic LE model applications.

\begin{tabular}{lll}
\hline \hline Case & Application area & Modelling \\
\hline \hline Gas furnace & Modelling & Tuning: training, validation, testing \\
Solar collector field & Controller tuning & $\begin{array}{l}\text { Time varying transport delay } \\
\text { Cloudy periods }\end{array}$ \\
Fatigue & Forecasting fatigue risk & $\begin{array}{l}\text { Cumulative sum of stress contributions } \\
\text { Rolling mill, LHD machines }\end{array}$ \\
Water treatment & Controller tuning & $\begin{array}{l}\text { Water quality indicator } \\
\text { Water circulation, Drinking water }\end{array}$ \\
Condition monitoring & Prognostics & Recursive tuning \\
\hline \hline
\end{tabular}

\subsection{Nonlinear parameter (NPV) models}

The LE models are defined by the parameters of the scaling functions and the coefficients of the interaction models. The idea of the exogenous variables can be used for these parameters, which opens a set of new modelling approaches for the nonlinear parameter (NPV) varying models. There are three levels of complexity: (1) individual scaling functions are compressed or expanded, (2) the shape of the functions is modified, and (3) also the coefficients of the equations are modified.

Clustering methodologies are used for finding areas for the submodels. The clustering variables define the operating conditions are not necessarily included in the submodels.

\subsection{Genetic tuning}

Evolutionary computing is widely used to tune intelligent systems which incorporate expert knowledge with data. Genetic algorithms are well suited for LE models based on nonlinear scaling and linear interactions. The scaling functions handle efficiently the parameter constraints of the monotonously increasing second order polynomials and the whole system is configured with a set of parameters. (Juuso, 2009a)

\section{Applications}

Nonlinear scaling forms the basis for the LE modelling: an important benefit of the linear approach is that the models can be inverted, technically to any direction. The compact basic solution makes extensions to dynamic and casebased systems possible. Complex models for steady-state and dynamic systems can be built with the cascade and interactive structures.

\subsection{Steady-state LE models}

Steady-state LE models are mainly used in adaptation and feedforward control (Table 1). In most cases, the models include only a single linear equation. The first LE model developed for designing submerged arc furnaces was an exception which used well known relations represented by five equations (Juuso and Leiviskä, 1992). A steady-state LE model was developed in an early control application from the process measurements of a lime kiln (Juuso et al., 1997). For continuous cooking, a LE model has been developed for predicting the Kappa number, which is widely used quality variable (Leiviskä et al., 2001).

The working point model presented in (Juuso et al., 1998) is still an essential part of the model-based LE control of a solar power plant (Juuso and Yebra, 2013). Stresscycle (S-N) curves, also known as Wöhler curves, are rep- 
Table 3. Decomposed LE model applications.

\begin{tabular}{|c|c|c|}
\hline Case & Application area & Modelling \\
\hline Lime kiln & $\begin{array}{l}\text { Fuel quality } \\
\text { Adaptive control }\end{array}$ & Controller tuning by using multiple models \\
\hline Solar collector field & Controller tuning for oil flow & $\begin{array}{l}\text { Models for different operating conditions } \\
\text { Distributed parameter models }\end{array}$ \\
\hline Batch cooking & On-line forecasting & $\begin{array}{l}\text { Three interactive models: alkali, lignin } \\
\text { and dissolved solids }\end{array}$ \\
\hline Fluidised bed granulation & Forecasting & $\begin{array}{l}\text { Three interactive models: } \\
\text { temperature, humidity and granular size }\end{array}$ \\
\hline Fed-batch fermentation & On-line forecasting & $\begin{array}{l}\text { Submodels of three growth phases, } \\
\text { each including three interactive models, } \\
\text { totally nine interactive models }\end{array}$ \\
\hline Wastewater treatment & $\begin{array}{l}\text { Detection of operating } \\
\text { conditions }\end{array}$ & $\begin{array}{l}\text { Three submodels: load, treatment and settling } \\
\text { Trend analysis }\end{array}$ \\
\hline
\end{tabular}

resented by a linguistic equation (Juuso and Ruusunen, 2013).

In drinking water applications, models have been developed for forecasting and control (Tomperi et al., 2013). Operating conditions are detected in diagnosing the wastewater treatment process (Juuso and Laakso, 2013).

\subsection{Dynamic LE models}

The basic dynamic LE model is represented by the parametric model (1) with an appropriate number of variables. The approach was first tested in a gas furnace data provided by (Box and Jenkins, 1970). The dynamic models of the solar plant are based on test campaigns, which cannot be planned in detail because of changing weather conditions (Juuso, 2003a). The basic dynamic flotation model is the core of the quality indicator in water treatment (Ainali et al., 2002; Joensuu et al., 2005). A dynamic LE model has been used for the fatigue prediction in (Juuso and $\mathrm{Ru}-$ usunen, 2013). In all these models, only one equation is needed. The applications are indirect measurements and controller tuning (Table 2). Drinking water applications focus on model-based control and forecasting (Tomperi et al., 2016). Trend analysis is important in the wastewater treatment (Tomperi et al., 2017).

\subsection{Decomposition in LE models}

The multimodel LE system can include several submodels and complex interactions (Table 3). All basic models are represented by the model (1) with an appropriate number of variables.

The model with a fuzzy decision module was first used for a lime kiln (Juuso, 1999b) and then for a solar thermal power plant (Juuso, 2003a). The lime kiln model had six operating areas defined by the production level and the trend of the fuel feed (increasing, decreasing). The model of the collector field includes four operating areas: startup, low, normal and high operation. For handling special situations in the solar plant, additional fuzzy models have been developed by using the Fuzzy-ROSA method (Juuso et al., 2000). Interactive dynamic models were needed in several cases: batch cooking (Juuso, 2003b), fluidised bed granulator (Mäki et al., 2004), industrial fed-batch fermenter (Saarela et al., 2003) and wastewater treatment (Juuso et al., 2009). Linguistic equations, neural networks and fuzzy modelling with several variants have been compared by using the process data obtained from the fedbatch fermenter.

\subsection{Distributed parameter LE models}

In the distributed parameter models, the solar collector field is divided into modules, where the dynamic LE models are applied in a distributed way (Juuso, 2004b). The same single equation model (1) with an appropriate number of variables is used in all modules. Element locations for partial differential equations (PDEs) are defined by the flow rate. In cloudy conditions, the heating effect can be strongly uneven.

\section{Discussion}

The nonlinear scaling methodology is the key in the extensions of the linear methodologies. Steady-state models form the basis and extended to dynamic applications with additional structures. Several steady-state and dynamic models are combined with fuzzy set systems. The ensemble averaging could be used in the neural computing with linear networks. Distributed parameter systems can use the same algorithms. All the applications discussed in Section 4 use the scaling functions explained in Section 2.1.1 have been developed before the current data-based analysis. Clustering is used in finding the areas of the submodels.

All parameters of the multimodel LE systems can be tuned with genetic algorithms. Constraints are taken into account in the coding which means that penalties are not needed in the optimisation. 
The variable specific recursive analysis of the parameters of the scaling functions is feasible for the machine learning phase. The multimodel structure facilitates deep learning extensions.

\section{Conclusions}

The nonlinear scaling approach extends the application areas of linear methodologies to nonlinear modelling: the meanings of variables and interactions are analysed sequentially. Local nonlinear models reduce the need for decomposition with local models. The close connection to the fuzzy set systems provides a good basis for understandable models. Data-based methodologies are suitable for developing models for decomposed systems. Big data problems are solved level by level to keep the domain expertise as an essential part of the solution. The basic models are compact and additional properties, including dynamics, uncertainty and decomposition are included if needed.

\section{Acknowledgment}

The combined approach has been developed within the research program Measurement, Monitoring and Environmental Efficiency Assessment (MMEA) on the basis of several earlier and parallel projects.

\section{References}

I. Ainali, M. Piironen, and E. Juuso. Intelligent water quality indicator for chemical water treatment unit. In Proceedings of SIMS 2002 - the 43rd Scandinavian Conference on Simulation and Modelling, September 26-27, 2002, Oulu, Finland, pages 247-252. Oulu, 2002.

D. Anguita. Smart adaptive systems - state of the art and future directions for research. In Proceedings of Eunite 2001 - European Symposium on Intelligent Technologies, Hybrid Systems and their implementation on Smart Adaptive Systems, July 13-14, 2001, Tenerife, Spain, pages 1-4. Wissenschaftsverlag Mainz, Aachen, 2001.

R. Babuška. Fuzzy Modeling and Identification. Kluwer Academic Publisher, Boston, 1998.

R. Babuška and H. Verbruggen. Neuro-fuzzy methods for nonlinear system identification. Annual Reviews in Control, 27 (1):73-85, 2003.

G. E. P. Box and G. M. Jenkins. Time Series Analysis, Forecasting and Control. Holden Day, San Francisco, 1970.

G. E. P. Box and K. B. Wilson. On the experimental attainment of optimum conditions. Journal of the Royal Statistical Society. Series B, 13(1):1-45, 1951.

J. J. Buckley and T. Feuring. Universal approximators for fuzzy functions. Fuzzy Sets and Systems, 113:411-415, 2000.

J. J. Buckley and Y. Hayashi. Can neural nets be universal approximators for fuzzy functions? Fuzzy Sets and Systems, 101:323-330, 1999.
J. J. Buckley and Y. Qu. On using $\alpha$-cuts to evaluate fuzzy equations. Fuzzy Sets and Systems, 38(3):309-312, 1990.

F. J. Christophersen. Piecewise Affine Systems. In M. M. Gupta and T. Yamakawa, editors, Optimal Control of Constrained Piecewise Affine Systems, Lecture Notes in Control and Information Sciences, volume 359, pages 39-42. Springer, Berlin, Heidelberg, 2007. doi:10.1007/978-3-540-72701-9_4.

M. De Cock and E. E. Kerre. Fuzzy modifiers based on fuzzy relations. Information Sciences, 160(1-4):173-199, 2004.

D. Driankov, H. Hellendoorn, and M. Reinfrank. An Introduction to Fuzzy Control. Springer, Berlin, Germany, 1993.

D. Dubois, H. Prade, and L. Ughetto. Fuzzy logic, control engineering and artificial intelligence. In H. B. Verbruggen, H.J. Zimmermann, and R. Babuska, editors, Fuzzy Algorithms for Control, International Series in Intelligent Technologies, pages 17-57. Kluwer, Boston, 1999.

R. Fullér. Introduction to Neuro-Fuzzy Systems. Advances in Soft Computing. Springer, 2000. 289 pp.

R. W. Gerlach, B. R. Kowalski, and H. O. A. Wold. Partial least squares modelling with latent variables. Anal. Chim. Acta, 112(4):417-421, 1979.

A. Hjartarson, P. Seiler, and A. Packard. LPVTools: A toolbox for modeling, analysis, and synthesis of parameter varying control systems. IFAC-PapersOnLine, 48(26):139-145, 2015. URL www. scopus. com.

J.-S. R. Jang. ANFIS: Adaptive-Network-based Fuzzy Inference Systems. IEEE Transactions on Systems, Man, and Cybernetics, 23(3):665-685, 1993.

A. K. S. Jardine, D. Lin, and D. Banjevic. A review on machinery diagnostics and prognostics implementing conditionbased maintenance. Mechanical Systems and Signal Processing, 20(7):1483-1510, 2006.

I. Joensuu, M. Piironen, and E. Juuso. Dynamic simulator for dosing of water treatment chemicals. Computer-aided chemical engineering, European Symposium on Computer Aided Process Engineering-15 (Escape-15), Barcelona, Spain, May 29 - June 1, 2005, 20A:301-306, 2005.

I. T. Jolliffe. Principal Component Analysis. Springer, New York, 2 edition, 2002. 487 pp.

E. Juuso and I. Laakso. Hybrid le systems for simulation of an activated sludge process. In Proceedings - 8th EUROSIM Congress on Modelling and Simulation, EUROSIM 2013, 10-13 September, 2013, Cardiff, UK, pages 124-129, 2013. doi:10.1109/EUROSIM.2013.32. URL www . s copus . com.

E. Juuso and S. Lahdelma. Intelligent scaling of features in fault diagnosis. In 7th International Conference on Condition Monitoring and Machinery Failure Prevention Technologies, CM 2010 - MFPT 2010, 22-24 June 2010, Stratfordupon-Avon, UK, volume 2, pages 1358-1372, 2010. URL WwW. scopus. com. 
E. Juuso and M. Ruusunen. Fatigue prediction with intelligent stress indices based on torque measurements in a rolling mill. In 10th International Conference on Condition Monitoring and Machinery Failure Prevention Technologies, CM 2013 MFPT 2013, 18-20 June 2013, Krakow, Poland, volume 1, pages 460-471, 2013. URL www. scopus . com.

E. Juuso, T. Latvala, and I. Laakso. Intelligent analysers and dynamic simulation in a biological water treatment process. In I. Troch and F. Breitenecker, editors, 6th Vienna Conference on Mathematical Modelling - MATHMOD 2009, February 11-13, 2009, Argesim Report no. 35, pages 999-1007. Argesim, 2009. ISBN 978-3-901608-35-3.

E. K. Juuso. Fuzzy control in process industry: The linguistic equation approach. In H. B. Verbruggen, H.-J. Zimmermann, and R. Babuška, editors, Fuzzy Algorithms for Control, International Series in Intelligent Technologies, volume 14 of International Series in Intelligent Technologies, pages 243300. Kluwer, Boston, 1999a. doi:10.1007/978-94-011-44056_10.

E. K. Juuso. Intelligent dynamic simulation of a lime kiln with linguistic equations. In H. Szczerbicka, editor, ESM'99: Modelling and Simulation: A tool for the Next Millenium, 13th European Simulation Multiconference, Warsaw, Poland, June 1-4, 1999, pages 395-00, Delft, The Netherlands, 1999b. SCS.

E. K. Juuso. Intelligent dynamic simulation of a solar collector field. In A. Verbraeck and V. Hlupic, editors, Simulation in Industry, 15th European Simulation Symposium ESS 2003, pages 443-449. SCS, Gruner Druck, Erlangen, Germany, 2003a.

E. K. Juuso. Intelligent dynamic simulation of batch cooking. In 44th Scandinavian Conference on Simulation and Modeling SIMS 2003, September 18 -19, 2003, pages 163-169. Malardalen University, Västeras, Sweden, 2003b.

E. K. Juuso. Integration of intelligent systems in development of smart adaptive systems. International Journal of Approximate Reasoning, 35(3):307-337, 2004a. doi:10.1016/j.ijar.2003.08.008.

E. K. Juuso. Dynamic simulation of a solar collector field with intelligent distributed parameter models. In B. Elmegaard, Jon Sporring, Kenny Erleben, and Kim Soerensen, editors, Proceedings of SIMS 2004 - the 45th Scandinavian Conference on Simulation and Modelling, September 23-24, Copenhagen, Denmark, pages 141-153. DTU, Lungby, Denmark, 2004b.

E. K. Juuso. Tuning of large-scale linguistic equation (LE) models with genetic algorithms. In M. Kolehmainen, editor, Revised selected papers of the International Conference on Adaptive and Natural Computing Algorithms - ICANNGA 2009, Kuopio, Finland, Lecture Notes in Computer Science, volume LNCS 5495, pages 161-170. Springer-Verlag, Heidelberg, 2009a. doi:10.1007/978-3-642-04921-7_17.

E. K. Juuso. Development of multiple linguistic equation models with Takagi-Sugeno type fuzzy models. In J. P. Carvalho, D. Dubois, U. Kaymak, and J. C. M. Sousa, editors, Proceedings of 2009 IFSA World Congress /
2009 EUSFLAT Conference, July 20-24, 2009, Lisboa, Portugal, pages 1779-1784. IFSA-EUSFLAT, 2009b. http://www.eusflat.org/publications_proceedings_IFSAEUSFLAT_2009.php.

E. K. Juuso. Recursive tuning of intelligent controllers of solar collector fields in changing operating conditions. In S. Bittani, A. Cenedese, and S. Zampieri, editors, Proceedings of the 18th World Congress The International Federation of Automatic Control, Milano (Italy) August 28 - September 2, 2011, pages 12282-12288. IFAC, 2011. doi:10.3182/20110828-6-IT-1002.03621.

E. K. Juuso. Intelligent methods in modelling and simulation of complex systems. Simulation Notes Europe SNE, 24(1):1-10, 2014. doi:10.11128/sne.24.on.102221.

E. K. Juuso and K. Leiviskä. Adaptive expert systems for metallurgical processes. In S.-L. Jämsä-Jounela and A. J. Niemi, editors, Expert Systems in Mineral and Metal Processing, IFAC Workshop, Espoo, Finland, August 26-28, 1991, IFAC Workshop Series, 1992, Number 2, pages 119-124, Oxford, UK, 1992. Pergamon.

E. K. Juuso and L. J. Yebra. Model-based intelligent control of a solar energy collector field. In Proceedings - 8th EUROSIM Congress on Modelling and Simulation, EUROSIM 2013, 10-13 September, 2013, Cardiff, UK, pages 513-518, 2013. doi:10.1109/EUROSIM.2013.92. URL www . s copus . com.

E. K Juuso, T. Ahola, and K. Leiviskä. Fuzzy modelling of a rotary lime kiln using linguistic equations and neurofuzzy methods. In L. Foulloy, editor, Proceedings of the 3rd IFAC Symposium on Intelligent Components and Instruments for Control Applications - SICICA'97, Annecy, France, June 9-11, 1997, pages 579-584. Pergamon, 1997. ISBN 9780080426082 .

E. K. Juuso, P. Balsa, and L. Valenzuela. Multilevel linguistic equation controller applied to a $1 \mathrm{MW}$ solar power plant. In Proceedings of the ACC'98, Philadelphia, PA, June 24-26, 1998, volume 6, pages 3891-3895. ACC, 1998.

E. K. Juuso, D. Schauten, T. Slawinski, and H. Kiendl. Combination of linguistic equations and the fuzzy-ROSA method in dynamic simulation of a solar collector field. In L. Yliniemi and E. Juuso, editors, Proceedings of TOOLMET 2000 Symposium - Tool Environments and Development Methods for Intelligent Systems, Oulu, April 13-14, 2000, pages 63-77, Oulu, 2000. Oulun yliopistopaino.

V.-H. Le and D.-K. Tran. Extending fuzzy logics with many hedges. Fuzzy Sets and Systems, 345:126 - 138, 2018. ISSN 0165-0114. doi:10.1016/j.fss.2018.01.014. Theme : Logic.

K. Leiviskä, E. Juuso, and A. Isokangas. Intelligent modelling of continuous pulp cooking. In K. Leiviskä, editor, Industrial Applications of Soft Computing, Studies in Fuzziness and Soft Computing, pages 147-158. Springer, Heidelberg, 2001. doi:10.1007/978-3-7908-1822-2_10.

L. Ljung. System Identification - Theory for the User. Prentice Hall, Upper Saddle River, N.J., 2nd edition, 1999. 
L. Ljung. Perspectives on system identification. In M. J. Chung and P. Misra, editors, Plenary papers, milestone reports \& selected survey papers, 17th IFAC World Congress, Seoul, Korea, July 6-11, 2008, pages 47-59. IFAC, 2008. http://www.ifac-papersonline.net/.

T. Mäki, E. Juuso, and K. Leiviskä. Fuzzy modelling and dynamic simulation of a fluidised bed granulator. In K. Leiviskä, editor, Proceedings of AFNC'04 - the 2nd IFAC Workshop on Advanced Fuzzy/Neural, September 16-17, 2004, Oulu, Finland, pages 133-138. Finnish Automation Society, Helsinki, 2004.

J. M. Mendel. Advances in type-2 fuzzy sets and systems. Information Sciences, 177(1):84-110, 2007.

R. E. Moore. Interval Analysis. Prentice Hall, Englewood Cliffs, NJ, 1966.

M. M. Najafabadi, F. Villanustre, T. M. Khoshgoftaar, N. Seliya, R. Wald, and E. Muharemagic. Deep learning applications and challenges in big data analytics. Journal of Big Data, 2 (1):1-21, Feb 2015. doi:10.1186/s40537-014-0007-7.

D. E. Rummelhart, G. E. Hinton, and R. J. Williams. Learning internal representations by error propagation. In D. E. Rummelhart and J. McClelland, editors, Parallel Data Processing, pages 318-362. M.I.T. Press, Cambridge, MA, 1986.

U. Saarela, K. Leiviskä, E. Juuso, and A. Kosola. Modelling of a fed-batch enzyme fermentation process. In IFAC International Conference on Intelligent Control Systems and Signal Processing. Faro, Portugal, April 8-11, 2003. IFAC, 2003.

A. Sadeghian, J.M. Mendel, and H. Tahayori. Advances in Type2 Fuzzy Sets and Systems: Theory and Applications. Studies in Fuzziness and Soft Computing. Springer New York, 2013. ISBN 9781461466666. URL https: / / books . google. fi/books? id=1SO7BQAAQBAJ.

H.K. Sahoo, P.K. Dash, and N.P. Rath. Narx model based nonlinear dynamic system identification using low complexity neural networks and robust $\mathrm{H} \infty$ filter. Applied Soft Computing, 13(7):3324 - 3334, 2013. ISSN 1568-4946. doi:10.1016/j.asoc.2013.02.007.

J. Schmidhuber. Deep learning in neural networks: An overview. Neural Networks, 61 (Supplement C):85 - 117, 2015. ISSN 0893-6080. doi:https://doi.org/10.1016/j.neunet.2014.09.003. URL http://www.sciencedirect.com/science/ article/pii/s0893608014002135.

E. Sontag. Nonlinear regulation: The piecewise linear approach. IEEE Transactions Automatic Control, 26(2):346-358, 1981.

T. Takagi and M. Sugeno. Fuzzy identification of systems and its applications to modeling and control. IEEE Transactions on Systems, Man, and Cybernetics, 15(1):116-132, 1985.

J. Theis, P. Seiler, and H. Werner. LPV model order reduction by parameter-varying oblique projection. IEEE Transactions on Control Systems Technology, 26(3):773-784, 2018. URL www. scopus. com.
J. Tomperi, E. Juuso, and K. Leiviskä. Hybrid le systems for simulation of an activated sludge process. In Proceedings 8th EUROSIM Congress on Modelling and Simulation, EUROSIM 2013, 10-13 September, 2013, Cardiff, UK, pages 118-123, 2013. doi:10.1109/EUROSIM.2013.31. URL wWw. scopus. com.

J. Tomperi, E. Juuso, and K. Leiviskä. Early warning of changing drinking water quality by trend analysis. Journal of Water and Health, 14(3):433-442, 2016. doi:10.2166/wh.2016.330.

J. Tomperi, E. Juuso, A. Kuokkanen, and K. Leiviskä. Monitoring a municipal wastewater treatment process using a trend analysis. Environmental Technology (United Kingdom), pages 1-10, 2017. doi:10.1080/09593330.2017.1375026.

N. Vafamand, M. Mehdi Arefi, and A. Khayatian. Nonlinear system identification based on Takagi-Sugeno fuzzy modeling and unscented kalman filter. ISA Transactions, 74:134 - 143, 2018. ISSN 0019-0578. doi:10.1016/j.isatra.2018.02.005.

M. Valle. Smart Adaptive Systems on Silicon. Springer US, 1 edition, 2004. doi:10.1007/978-1-4020-2782-6.

Y.-W. Xiao, J. Wu, Z.-G. Lin, and X.-D. Zhao. A deep learningbased multi-model ensemble method for cancer prediction. Computer Methods and Programs in Biomedicine, 153:1 - 9, 2018. ISSN 0169-2607. doi:10.1016/j.cmpb.2017.09.005.

D.-K. Xu and Y.-J. Tian. A comprehensive survey of clustering algorithms. Annals of Data Science, 2(2):165-193, Jun 2015. ISSN 2198-5812. doi:10.1007/s40745-015-0040-1.

L. A. Zadeh. Fuzzy sets. Information and Control, 8(June): 338-353, 1965.

L. A. Zadeh. The Concept of a Linguistic Variable and Its Application to Approximate Reasoning-1. Information Sciences, 8: 199-249, 1975. 